\title{
Trade-offs, condition dependence and stopover site selection by migrating sandpipers
}

\author{
Ronald C. Ydenberg, Robert W. Butler, David B. Lank, Christopher G. Guglielmo, Moira Lemon and \\ Nicholas Wolf
}

\begin{abstract}
Ydenberg, R. C., Butler, R. W., Lank, D. B., Guglielmo, C. G., Lemon, M. and Wolf, N. 2002. Trade-offs, condition dependence and stopover site selection by
\end{abstract} migrating sandpipers. - J. Avian Biol. 33: 47-55.

\begin{abstract}
Western sandpipers Calidris mauri on southward migration fly over the Gulf of Alaska to the Strait of Georgia, British Columbia, where they stop for a few days to replenish reserves before continuing. In the Strait, individuals captured on the extensive tidal mudflats of the Fraser estuary ( $\sim 25000$ ha) are significantly heavier ( $2.71 \mathrm{~g}$, or $>10 \%$ of lean body mass) than those captured on the small $(<100 \mathrm{ha})$ mudflat of nearby Sidney Island. Previous work has shown that the difference cannot be attributed to seasonal timing, size, age or gender effects, and here we compare predictions made by six hypotheses about a diverse set of data to explain why, partway through a migratory journey of $\sim 10000 \mathrm{~km}$, birds have such different body masses at two stopover sites within $40 \mathrm{~km}$ of each other. The 'trade-off' hypothesis - that the large Fraser estuary offers safety from predators, but a lower fattening rate, while the small Sidney Island site is more dangerous, but offers a higher fattening rate - made six successful predictions, all of which were upheld by the data. All other hypotheses failed at least one prediction. We infer that calidrid sandpipers arriving in the Strait of Georgia with little fat remaining (and therefore low body mass) choose to take advantage of the high feeding rate at small sites like Sidney Island because they are less vulnerable to avian predators than are individuals with higher fat reserves, who instead elect to feed at large open sites like the Fraser estuary mudflats.
\end{abstract}

R. C. Ydenberg (correspondence), D. B. Lank and N. Wolf, Behavioral Ecology Research Group, and Department of Biological Sciences, Simon Fraser University, Burnaby, BC,V5A 1S6. E-mail: ydenberg@sfu.ca. R. W. Butler and M. Lemon, Canadian Wildlife Service, Pacific Wildlife Centre, RR1, 5421 Robertson Rd., Delta, British Columbia, V4K 3N2, Canada. D. B. Lank and C. G. Guglielmo, Centre for Wildlife Ecology, Department of Biological Sciences, Simon Fraser University Burn$a b y, B C$, V5A 1S6, Canada.

Recently, we reported (Lissimore et al. 1999) that among western sandpipers Calidris mauri migrating southward through the Strait of Georgia in British Columbia, Canada, those captured on the extensive tidal mudflats of the Fraser estuary were $2.71 \mathrm{~g}$ heavier (difference in overall average of annual means) than those captured on the small mudflat of Sidney Island, located only $35 \mathrm{~km}$ to the southwest (Fig. 1). Even larger differences occur within each of the two years (1996: $3.13 \mathrm{~g}$; and 1997: $7.65 \mathrm{~g}$ ) for which we have good samples from both sites.

These birds were on stopover after a long $(\sim 2500$ km) flight over the Gulf of Alaska from their breeding area in western Alaska (Butler et al. 1996), and individual birds spent only a few days in the Strait of Georgia before continuing southward. In this context, the observed weight difference is large and significant: if $80 \%$ fat, it represents a non-wind assisted flight range of 300-900 km (see Butler et al. 1997), at minimum easily large enough to fly to the next large stopover site at Gray's Harbor, Washington, $270 \mathrm{~km}$ to the south. Similar weight differences have been reported elsewhere. Bar-tailed godwits Limosa lapponica at a coastal site in The Netherlands were $40 \mathrm{~g}(\sim 10 \%)$ heavier than

(C) JOURNAL OF AVIAN BIOLOGY 
those feeding at the same time on an inland meadow only $100 \mathrm{~km}$ away (Piersma and Jukema 1993). Also, western sandpipers on northward migration are lighter at inland than at coastal sites (Warnock and Bishop 1998).

Such weight differences between nearby sites could be due to various biases, such as the seasonal timing (e.g. Lindström 1998) or the age/gender composition of samples from different sites. However, the difference we measured is found within every age and gender class, and holds throughout the summer-long passage period (Lissimore et al. 1999). A different idea is that the birds on the different sites could be from different populations and on different migratory routes or schedules (e.g. Dick et al. 1987), but this seems unlikely to apply to western sandpipers, as no subspecies or races of western sandpipers are recognized. Finally, the differences could arise from stopover site selection by individual birds that depends on their body mass or other condition factors. Here we investigate why western sandpipers have such different body masses at two nearby stopover sites located partway through a long migratory journey $(\sim 10000 \mathrm{~km})$. We use a variety of data on sandpiper migration to test predictions of six hypotheses.

\section{Methods}

The basic data are from 11109 western sandpipers captured in mist nets on the Fraser estuary and on Sidney Island (Fig. 1). Birds were banded, weighed ( $\pm 0.1 \mathrm{~g}$ ), aged (juvenile or adult, based on plumage), and wing length (flattened wing chord) and culmen were measured $( \pm 0.1 \mathrm{~mm})$. Gender was assigned based on culmen length (Page and Fearis 1971). Sandpipers were captured throughout the summer-long passage period at one site or the other in most years since 1978, and at both sites in 1996 and 1997. We also report data on 83 western sandpipers caught at Gray's Harbor and False Bay by O'Reilly (1995), who used similar methods. In addition, we captured and measured 2667 individuals of the congeneric least sandpiper Calidris minutilla; and 41 semipalmated sandpipers Calidris pusilla. All these data are summarized in Table 1.

As part of an international program between 1989 and 1995 (Butler et al. 1996), western sandpipers were fitted with leg flags, color-coded to represent the capture site. Many were marked at Chitré in Panamá, where two groups of several thousand western sandpipers are highly philopatric to individual beaches throughout the winter (P. D. O'Hara and F. Delgado unpubl. data). Western sandpipers breeding at Nome,

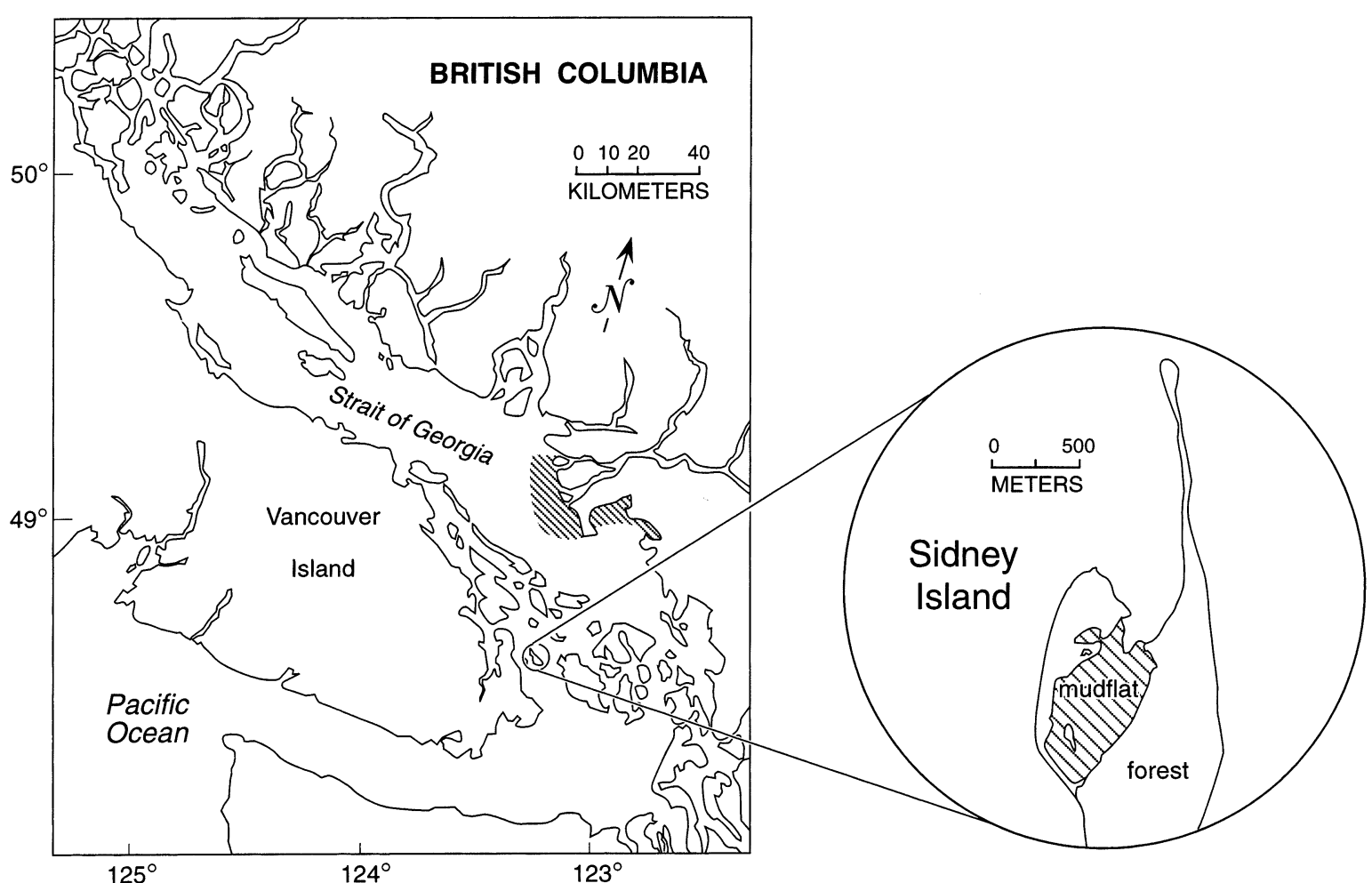

Fig. 1. Map of the southern Strait of Georgia, showing study sites. The extensive mudflats of the Fraser River estuary are shaded in the main map. Sidney Island is circled on the main map, and its mudflat shown on the inset. Grays Harbor is located $270 \mathrm{~km}$ south, on the Pacific coast of Washington State. 
Table 1. Comparisons of the body mass of southward migrating calidrid sandpiper species captured at large (Fraser estuary FE, Gray's Harbor GH) and small (Sidney Island SI, False Bay FB) stopover sites. Data for GH and FB from O'Reilly (1995). All differences are highly significant $(\mathrm{p}<0.0001)$.

\begin{tabular}{|c|c|c|c|c|c|}
\hline \multirow[t]{2}{*}{ Species } & \multirow[t]{2}{*}{ Location } & \multirow[t]{2}{*}{ Years } & \multicolumn{2}{|c|}{ Mean difference } & \multirow[t]{2}{*}{$\mathrm{n}$} \\
\hline & & & (g) & $(\%)$ & \\
\hline Western $^{1}$ & $\begin{array}{l}\text { FE } \\
\text { SI }\end{array}$ & $\begin{array}{r}8,1978-1997 \\
11,1985-1999\end{array}$ & $\begin{array}{l}27.34 \\
24.63\end{array}$ & $\begin{array}{c}2.71 \\
(9.9 \%)\end{array}$ & $\begin{array}{l}9480 \\
1629\end{array}$ \\
\hline Western & $\begin{array}{l}\text { FE } \\
\text { SI }\end{array}$ & 1,1996 & $\begin{array}{l}27.12 \\
23.99\end{array}$ & $\begin{array}{c}3.13 \\
(11.5 \%)\end{array}$ & $\begin{array}{l}334 \\
191\end{array}$ \\
\hline Western & $\begin{array}{l}\text { FE } \\
\text { SI }\end{array}$ & 1,1997 & $\begin{array}{l}31.55 \\
23.90\end{array}$ & $\begin{array}{c}7.65 \\
(24.2 \%)\end{array}$ & $\begin{array}{r}71 \\
299\end{array}$ \\
\hline Western ${ }^{2}$ & $\begin{array}{l}\text { GH } \\
\text { FB }\end{array}$ & $\begin{array}{r}3,1992-1994 \\
1,1991\end{array}$ & $\begin{array}{l}26.08 \\
23.39\end{array}$ & $\begin{array}{c}2.69 \\
(10.3 \%)\end{array}$ & $\begin{array}{l}65 \\
18\end{array}$ \\
\hline Least $^{1}$ & $\begin{array}{l}\text { FE } \\
\text { SI }\end{array}$ & $\begin{array}{r}10,1978-1997 \\
7,1985-1999\end{array}$ & $\begin{array}{l}23.22 \\
21.84\end{array}$ & $\begin{array}{l}1.38 \\
(5.6 \%)\end{array}$ & $\begin{array}{r}2121 \\
546\end{array}$ \\
\hline Least & $\begin{array}{l}\text { FE } \\
\text { SI }\end{array}$ & 1,1996 & $\begin{array}{l}24.79 \\
20.82\end{array}$ & $\begin{array}{c}3.97 \\
(16.0 \%)\end{array}$ & $\begin{array}{r}31 \\
113\end{array}$ \\
\hline Least & $\begin{array}{l}\text { FE } \\
\text { SI }\end{array}$ & 1,1997 & $\begin{array}{l}26.99 \\
21.03\end{array}$ & $\begin{array}{c}5.96 \\
(22.1 \%)\end{array}$ & $\begin{array}{r}90 \\
114\end{array}$ \\
\hline $\begin{array}{l}\text { Semi- } \\
\text { palmated }^{2}\end{array}$ & $\begin{array}{l}\text { FE } \\
\text { SI }\end{array}$ & 2, 1996-1997 & $\begin{array}{l}30.43 \\
22.59\end{array}$ & $\begin{array}{c}7.84 \\
(25.8 \%)\end{array}$ & $\begin{array}{l}31 \\
10\end{array}$ \\
\hline
\end{tabular}

${ }^{1}$ Mean of annual means. ${ }^{2}$ Mean of all data.

Alaska, were marked as part of a breeding study (Sandercock et al. 1999), and many birds captured at Sidney Island were color banded (e.g. Butler et al 1987). We collected resightings of all three of these groups of marked sandpipers.

To estimate fattening rates at the two sites, we measured plasma triglyceride concentration (total triglyceride - glycerol), which is positively related to the rate of body mass change in captive western sandpipers $\left(\mathrm{r}^{2}=0.40, \mathrm{p}<0.01\right.$; Williams et al. 1999), and also in garden warblers Sylvia borin (Jenni-Eiermann and Jenni 1994). The relevant periods of body mass change are one or two days (sandpipers) or hours (warblers) preceding the blood sample. In July and August 1996, we drew blood samples from actively feeding western sandpipers captured near the end of a high-low-high tide cycle, chosen so that birds at both sites had had maximum time to feed. Blood $(200-300 \mu \mathrm{l})$ was drawn into heparinized capillary tubes, centrifuged at $6000 \mathrm{rpm}$ for $10 \mathrm{~min}$ and plasma stored at $-20^{\circ} \mathrm{C}$. Metabolite analysis is described in Williams et al. (1999). Data were log-transformed to meet the assumptions of normality. Site comparisons were made after controlling for the effects of bleed-time (minutes after capture) and body mass (g) on triglyceride concentration. Males were excluded from the Fraser estuary data because of a significant interaction between sex and body mass at that site $(\mathrm{p}=0.04)$. However, inclusion of Fraser estuary males, or limitation of our analysis to females by dropping Sidney Island males does not alter our conclusions regarding site differences.

The main predators of calidrid sandpipers on our study sites are peregrines Falco peregrinus and merlins
Falco columbarius, but other raptors such as northern harriers Circus cyaneus and even glaucous-winged gulls Larus glaucescens hunt sandpipers on occasion (Dekker 1998). Falcons employ a variety of techniques when hunting sandpipers, but surprise substantially increases the probability of prey capture (Page and Whitacre 1975, Dekker 1988). On our study areas, peregrines usually hunt sandpipers close to the salt-marsh, where they use vegetation, dikes and other structures to cover their approach. Hunting success close to the salt-marsh is significantly higher ( $33 \%$ of hunts successful) than on open mudflats where there is no cover $(8 \%$; measurements reported by Dekker 1998 made on the Fraser estuary), confirming that areas close to cover are more dangerous for sandpipers.

We used the distance to cover of sandpipers feeding on the two sites (cf. Cowlishaw 1997) as a measure of site danger. Distance to cover was defined as the minimum distance at which an approaching predator potentially becomes visible to a sandpiper standing on the mudflat. For each randomly selected feeding sandpiper on Sidney Island, distance to cover was estimated by placing a $10 \mathrm{~cm}$ stake at the foraging location and maneuvering a $1 \mathrm{~m}$ tall post (representing a low-flying predator) behind nearby obstacles to find the shortest distance at which the line of sight between the tops of the two markers was barely obstructed. Analogous measurements were made on a representative section of the Fraser estuary (Boundary Bay) by calculating the distance from each bird to the salt marsh edge from measures made using a hand-held GPS with $+/-50$ $\mathrm{m}$ precision. Instantaneous tidal height estimates were obtained from the XTide program written by D. Flater (http://www.flaterco.com). 


\section{Testing six hypotheses}

Six hypotheses could potentially explain the different body weights of western sandpipers at the two sites. In this section we deduce and test (with the data described above) predictions made by these six hypotheses, aiming to generate a set of tests that together discriminate between the hypotheses.

\section{The population-structure hypothesis}

The first hypothesis is that different populations, wintering groups or ecotypes of western sandpipers use the two sites (cf. Morrison 1984, Dick et al. 1987). This seems unlikely to apply to western sandpipers as no subspecies or races are recognized. Moreover, our study sites are only $35 \mathrm{~km}$ apart, and both are used continuously over the extended southward migration period (late Juneearly September), as are a large number of other nearby sites. Also, the telemetry study of Iverson et al. (1996) showed that migrating western sandpipers use both large and small stopover sites. Nevertheless, groups of western sandpipers seem to be highly philopatric to specific wintering sites (P. D. O'Hara unpubl. data), and it is possible that they could have different migration routes and schedules, with different body weights. Under this hypothesis, members of one western sandpiper group should not be seen at both our Strait of Georgia study sites.

In three different and independent samples of marked birds, individuals have been located on both our study sites. (i) Twelve sightings have been made of birds flagged on the wintering areas at Chitré, in Panamá: eight were on the Fraser estuary, three at Sidney Island, and one at False Bay, another small mudflat site located in the Strait. (ii) Of western sandpipers marked on the breeding grounds near Nome, Alaska, two were located at Sidney Island and three on the Fraser estuary (Butler et al. 1996). (iii) Five birds banded at Sidney Island were later sighted on the Fraser estuary, and one of these was seen at both locations in the same year. Local movement is also demonstrated by two other same-season resightings of sandpipers banded at Sidney Island at other small sites in Georgia Strait, one at Cowichan Bay 27 km west; and one at Cordova Bay, $5 \mathrm{~km}$ south. These observations do not support the hypothesis of differential use of the sites by separate groups or populations, and are entirely consistent with use of both sites by birds from the same areas.

A second test of the population structure hypothesis concerns the body weights of other, related species at our two study sites. It seems unlikely a priori that other sandpiper species should have population structures leading them to use these sites in the same way and so demonstrate similar body mass differences. Least sandpipers, for example, have a breeding range and south- ward migration route quite different from western sandpipers, making parallel population differentiation exceedingly unlikely. Evidence of a similar body weight difference in other species would support an explanation common to small sandpiper species, rather than one peculiar to western sandpipers. Data on the body masses of other species prove that both least $(n=2667)$ and semipalmated sandpipers $(n=41)$ show a pattern of body masses across the two sites identical to that of western sandpipers (Table 1).

By the same logic, if the body mass difference is intrinsic to our two particular sites, there is no reason to suppose that similar sites at other locations should show the same pattern. Data from O'Reilly (1995) show that the body masses of southward migrating western sandpipers are significantly higher at Gray's Harbor $(n=65)$, a large stopover site, than at False Bay $(\mathrm{n}=18$, Table 1), a small site. The body masses are strikingly similar to those we measured at corresponding large (Fraser estuary) and small (Sidney Island) Strait of Georgia sites, and though involving only a single paired set of other sites, this does not support the population structure hypothesis.

Thus, none of these data provide any support for the population structure hypothesis. Instead, they implicate a general mechanism common to all three small sandpiper species and operational on other, similar sites.

\section{The capture-bias hypothesis}

Our second hypothesis is that the nature of the sites biases mist-net captures toward low-mass birds at Sidney Island and heavy individuals on the Fraser estuary. Such a capture bias could arise by several mechanisms. For example, at small sites new arrivals may be detected or mist-netted more easily, so that they are captured sooner after their migratory arrival than at large sites. Quicker capture means that birds would have had less time to replenish reserves, and hence would be lighter. This hypothesis would apply to other small calidridines, and to other sites.

The capture bias hypothesis makes a specific prediction about the shape of the cumulative frequency distributions of body masses on the two sites (Fig. 2). Under capture bias, the distributions should start at the same point, but rise more slowly on the Fraser estuary because individuals have on average spent more time feeding prior to capture. In contrast, on any facultative choice hypothesis (see below) whereby heavy individuals choose the Fraser estuary and light individuals Sidney Island, the frequency distribution should be shifted upwards by a constant amount at the Fraser estuary, as compared with Sidney Island.

We test these predictions against data on body masses of western sandpipers measured in 1996 and 1997, when sizeable samples of birds were captured at both sites. In 
these two years, the mean weight difference between sites was $3.96 \mathrm{~g}$. The lightest $1 \%$ of birds captured on each site differ by $2.50 \mathrm{~g}$, and less than $5 \%$ of the 405 western sandpipers caught on the Fraser estuary weighed less than $22 \mathrm{~g}$, compared to $25 \%$ (of 490) on Sidney Island. At the 25,50 , and $75 \%$ cumulative frequency marks, the weight differences are 3.2, 4.2, and $4.9 \mathrm{~g}$, respectively. No bird caught at Sidney Island weighed more than $32.1 \mathrm{~g}$, while $15 \%$ of the birds on the Fraser estuary did so. These data indicate that the body mass distribution at the Fraser estuary is shifted upwards from that at Sidney Island, but there is also an indication of some divergence, as predicted by capture bias.

For statistical evaluation, we calculated the distributions of body weight expected under facultative-choice and capture-bias models, and measured goodness-of-fit with the data using deviance values (D) calculated as
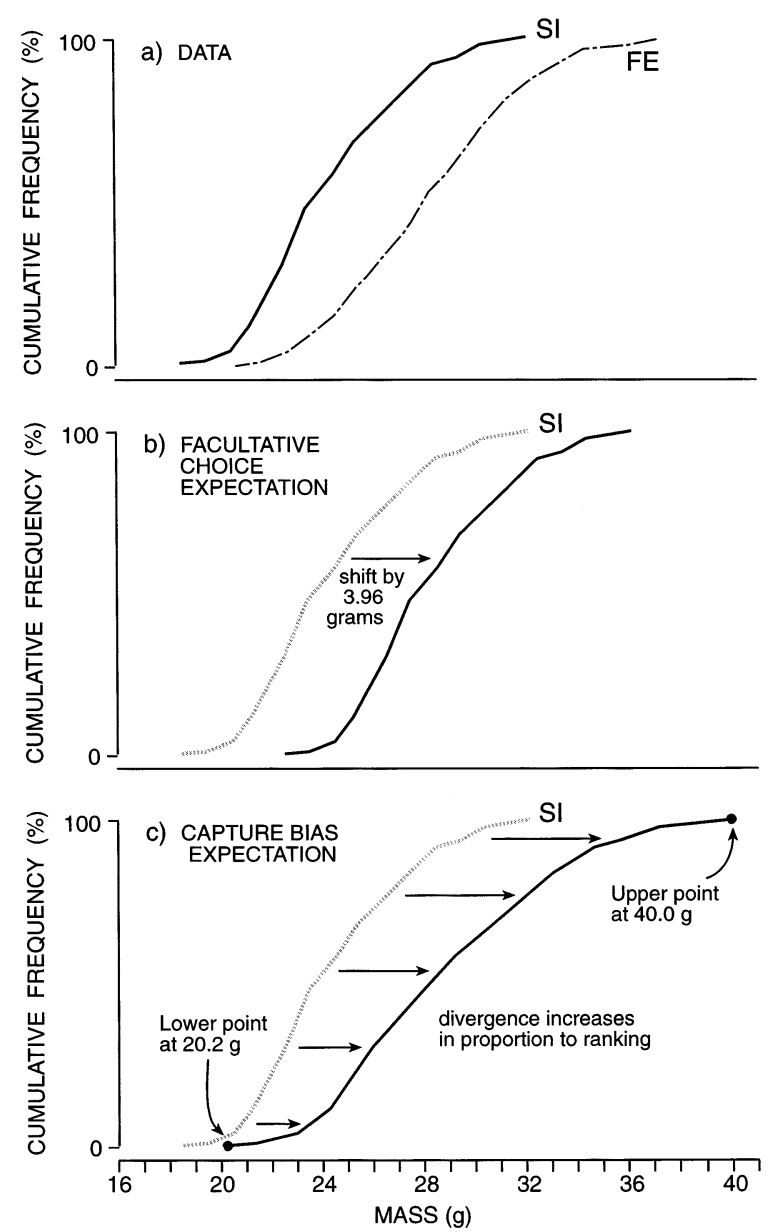

Fig. 2. Cumulative frequency distributions of body masses observed (a: upper panel) at Fraser estuary (FE; $\mathrm{n}=495)$ and Sidney Island (SI; $\mathrm{n}=405$ ); and an illustration of the methods used to create distributions expected under the facultative choice (b: middle panel) and capture bias hypotheses (c: lower panel). The expected distributions were based on the Sidney Island distribution and tested against the Fraser estuary distribution. See text for further details. absolute values of the differences between the cumulative expected and Fraser estuary distributions (Kolmogorov-Smirnov test, Zar 1984). If choice alone accounts for the difference, the cumulative frequency distributions on the two sites should have the same shape, and differ only in location (Fig. 2b). To create the expected distribution, we shifted the Sidney Island cumulative frequency distribution upward by a constant (the mean weight difference of $3.96 \mathrm{~g}$ ), and measured goodness-of-fit with the Fraser estuary data. In contrast, if capture bias alone accounts for the difference, cumulative frequency distributions on the two sites should begin at the same point and subsequently diverge (Fig. 2c). To create the expected distribution, we fixed the lower end of the expected distribution at the 5th percentile $(20.2 \mathrm{~g})$ of the Sidney Island distribution (which is more conservative than using the single lowest observed value of $18.0 \mathrm{~g}$ ) The upper end was fixed at the highest value observed on the Fraser estuary (40.0 g). Intermediate values of the expected distribution were generated by adjusting observed values on Sidney Island in direct proportion to their ranking.

Neither model fully accounted for the observed distribution, since the Fraser River data $(n=405)$ differed significantly from both expected distributions (Kolmogorov-Smirnov tests: facultative choice model, maximum $\mathrm{D}=0.372$; capture bias model, maximum $\mathrm{D}=0.098$; both $\mathrm{p}<0.0001)$. However, the magnitude of the deviations from expected values averaged 3.6 times larger under the capture bias than under the facultative choice model (choice mean $\mathrm{D}=0.060 \pm 0.006$ s.e., bias mean $\mathrm{D}=0.214 \pm 0.006$ s.e., the mean difference between models in $D$ values $=0.154 \pm 0.006$ s.e., $t=26.85$, $\mathrm{p}<0.0001)$. Thus the choice model provides a substantially better and significantly closer fit to the data than does the capture bias model.

To examine the capture-bias idea further, we calculated how long sandpipers would have had to be present on the Fraser estuary prior to capture to account for the overall mean difference of $2.71 \mathrm{~g}$ between sites by this mechanism alone. The mean daily rate of mass gain at Sidney Island was estimated at ca. $0.3 \mathrm{~g} \mathrm{~d}^{-1}$ by Butler and Kaiser (1995). If arrival masses and the mass gain rates are equivalent at the two sites, birds would on average have to be captured $9.0 \mathrm{~d}$ later into their stopover on the Fraser estuary to account fully for the difference. If the fattening rate is greater at Sidney Island than that on the Fraser estuary, as indicated by our data (see below), even longer would be required.

Stopover times measured by radiotelemetry on the Fraser estuary on northward migration average $3.6 \mathrm{~d}$ (Iverson et al. 1996). Butler et al. (1987) estimated a mean stopover duration of $1.7 \mathrm{~d}$ on Sidney Island on southward migration, but their capture-mark-resight method would have underestimated length of stay, perhaps by $100 \%$. Even so, the mean measured total stopover duration $(\sim 3.5 \mathrm{~d})$ is much shorter than the 


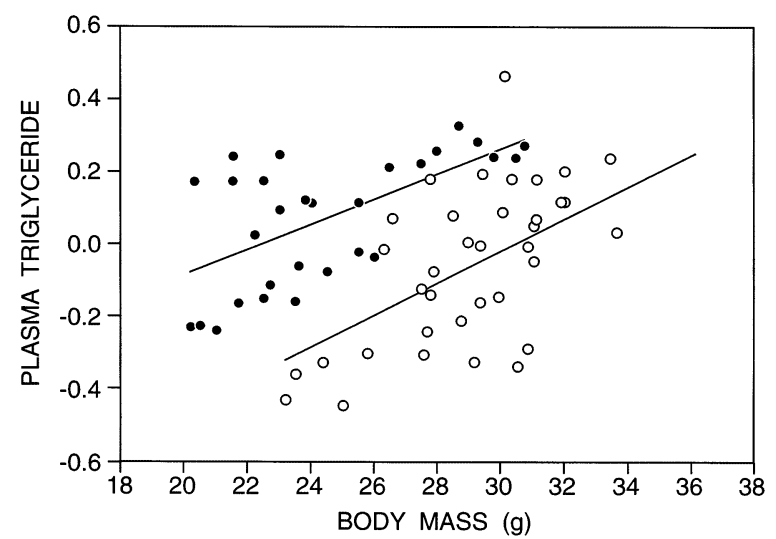

Fig. 3. Plasma triglyceride concentrations $\left(\mathrm{mmol} \mathrm{l}^{-1}\right)$ of western sandpipers $(n=66)$ captured on southward migration at Sidney Island (solid dots) and on the Fraser estuary (open dots). Data are residuals of $\log _{10}$ transformed plasma triglyceride concentration correcting for bleed-time, lines are least squares regressions. As found in captive studies (Williams et al. 1999), residuals are significantly related to body mass (Sidney Island, $\mathrm{r}^{2}=0.39, \mathrm{p}=0.0003$; Fraser estuary, $\mathrm{r}^{2}=0.33$, $\mathrm{p}=0.0002)$. There is no site $\times$ mass interaction $(\mathrm{p}=0.56)$ and no time of day effect at either site $(\mathrm{p}=0.16)$. Controlling for body mass, plasma triglyceride concentration is significantly higher at Sidney Island $(\mathrm{p}=0.0001)$

additional time required (9 d) to explain the body mass difference by the capture bias mechanism. Butler and Kaiser's (1995) fattening rate estimate of $0.3 \mathrm{~g} \mathrm{~d}^{-1}$ is perhaps an underestimate, but even if the true fat gain rates are much higher (say $0.7 \mathrm{~g} \mathrm{~d}^{-1}$ on the Fraser estuary and $1.0 \mathrm{~g} \mathrm{~d}^{-1}$ at Sidney Island), the capture bias hypothesis would still require a stopover longer by 3-5 $\mathrm{d}$ to explain fully the difference in body masses, which exceeds the total measured length of stay.

Our overall conclusion is that capture bias is unable to explain more than a small proportion of the difference in body weights between the two study sites.

\section{The fill-in hypothesis}

The four remaining hypotheses suppose that, upon arrival in the Strait of Georgia, individuals with small reserves choose to stopover at Sidney Island (or other small sites like it), while those with larger reserves choose the Fraser estuary. The observed difference in body mass between the sites arises as a consequence of their decisions.

The fill-in hypothesis (O'Reilly 1995) posits that inferior stopover sites are used only by individuals whose fat reserves are too low to complete the current migratory leg to the next preferred site. This seems unlikely in this case, as the flight distance between Sidney Island and the Fraser estuary is only $35 \mathrm{~km}$ (at the end of a $2500 \mathrm{~km}$ flight), and under prevailing wind directions new arrivals are likely to encounter the Fraser estuary first. The fill-in hypothesis is also unable to accommodate very easily the observation that least sandpipers (with a different migratory route) show the same body mass difference, or to explain why an unrelated pair of large and small sites also show a body mass difference. Nevertheless, it remains a logical possibility, and its main prediction is that Sidney Island site is inferior to the Fraser estuary for feeding.

The data refute this hypothesis. The least squares mean concentration of triglyceride in the plasma of sandpipers at Sidney Island $\left(4.16 \mathrm{mmol} \mathrm{l}^{-1}\right)$ is more than twice that at the Fraser estuary $\left(2.04 \mathrm{mmol}^{-1} ; \mathrm{n}=66 ; \mathrm{p}<0.0001\right.$; Fig. 3). This analysis includes adults and juveniles at the Fraser estuary, but only juveniles at Sidney Island (too few adults were captured at Sidney Island for valid comparison). However, even if the data are limited to juvenile females only, the difference between sites remains highly significant $(\mathrm{p}=0.0001)$, so the fattening difference is unlikely to be attributable to differences in the quality of birds. The conclusion is that western sandpipers are able to fatten more rapidly at Sidney Island.

\section{The ideal free hypothesis}

Hypothesis four is that the distribution of the sandpipers reflects a phenotype-limited ideal free distribution (Sutherland and Parker 1985), in which the difference in body masses between the two sites results because superior competitors (presumably the heavier birds, in this case) dominate at the better site. As shown in the previous section, however, Sidney Island is the better feeding location, and lighter, not heavier, birds feed there. Further, the body weight difference is found within every age/gender class (Lissimore et al. 1999). While this hypothesis could perhaps explain why related sandpiper species show the same mass difference across these two sites, it would have difficulty explaining why similar mass differences are observed at other large and small sites.

\section{The variance-sensitivity hypothesis}

The fifth hypothesis postulates a variance-sensitive choice (Stephens and Krebs 1986), with lighter birds preferring more variable sites. Guillemette et al. (1992) found that two major feeding habitats of common eiders Somateria mollissima wintering in the Gulf of St. Lawrence offered approximately the same total daily gain, but due to the rarer and larger prey items available in one habitat, the variance in daily gain was greater and birds in poor condition fed there. Yellow-rumped warblers Dendroica coronata are known to prefer variable feeding choices during fat buildup for migration (Moore and Simm 1986). This could explain the body mass difference described here if Sidney Island offered a more variable fattening rate. It could also explain why other, closely-related sandpiper species, presumably with similar diets, show the same mass difference. 
However, the critical prediction about variance is not supported. There is no significant difference between the standard deviations of plasma triglyceride concentrations of western sandpipers measured at the two sites (Fraser estuary $\mathrm{SD}=1.84 \mathrm{mmol}^{-1}, \mathrm{n}=37$ : Sidney Island $\mathrm{SD}=1.42 \mathrm{mmol}^{-1}, \mathrm{n}=29 . \mathrm{F}_{14,28}=1.66, \mathrm{NS}$ ). If anything, variance is higher on the Fraser estuary.

\section{The trade-off hypothesis}

The final hypothesis postulates a trade-off between feeding rate and predation risk, with one site offering better feeding, but at the same time posing more predation danger (Lima and Dill 1990, Houston et al. 1993, Cresswell 1994). Sidney Island appears to offer better feeding, so the hypothesis requires that it be more dangerous. The hypothesis assumes that birds with smaller fat deposits are less vulnerable to predators, making the better feeding at Sidney worth the extra risk, while the Fraser estuary would be the better choice for heavier, more vulnerable, individuals.

The idea that carrying fat puts birds at risk from predators has been invoked in theoretical treatments of body-mass regulation of birds in winter (e.g. Lima 1986) and on migration (Alerstam and Lindström 1990, Houston 1999). Empirical tests of fat load on escape flight performance indicate that migrants are slowed by the fat they carry (van der Veen and Lindström 2000), and our field measurements (Burns and Ydenberg unpubl. data) show that increased wingloading reduces take-off performance of migrating western and least sandpipers. We surmise that sandpipers carrying more fat are more vulnerable to predators.
Sidney Island appears to be more dangerous. At both sites, feeding sandpipers move closer to cover on a rising tide and move further away as the tide falls ( $\mathrm{y}$ is distance to cover (m) and $\mathrm{x}$ is tidal height $(\mathrm{m}), \mathrm{SI}: \mathrm{y}=157-66 \mathrm{x}$, $\mathrm{n}=30, \mathrm{r}^{2}=0.66, \mathrm{p}<0.0001$; FE: $\mathrm{y}=4297-834 \mathrm{x}, \mathrm{n}=$ $\left.19, \mathrm{r}^{2}=0.58, \mathrm{p}<0.0001\right)$. The change in distance to cover with change in tidal height is much less at Sidney Island ( 66 vs. $834 \mathrm{~m}$ of distance per $\mathrm{m}$ tidal height), but the overall mean distance to cover on the Fraser estuary is more than 30 times that at Sidney Island (SI: $87.3 \mathrm{~m}$; FE: $2911 \mathrm{~m}$ ). At the mean tidal height of the observations of $1.298 \mathrm{~m}$ this translates to a mean distance-to-cover of $49 \mathrm{~m}$ at Sidney Island and $2971 \mathrm{~m}$ at Fraser estuary, different by a factor of 60 . Moreover, the mudflat at Sidney Island is small ( $<100 \mathrm{ha}$ ) and almost completely enclosed by forest, dune ridges and salt-marsh vegetation, and there is a forested island in the lagoon. All these features provide approach cover for hunting raptors. In contrast, the horizon-to-horizon vistas on the Fraser estuary mudflats allow sandpipers to spot predators at great distances. This contrast suggests that the Fraser estuary is a safer feeding place than is Sidney Island.

\section{Discussion}

Of the six hypotheses we considered, the trade-off hypothesis was most strongly supported (Table 2). Its predictions were all upheld, while other hypotheses failed one or more predictions. Moreover, none made a successful prediction that was not shared with the trade-off hypothesis, and the predictions that Sidney Island is a better and more dangerous feeding site were unique to the trade-off hypothesis.

Table 2. Summary of the match between observations and the predictions of six hypotheses to explain why sandpipers are lighter at Sidney Island than on the Fraser estuary. 'yes' means the hypothesis predicts the observation, 'no' means the hypothesis is not supported. '" means that the hypothesis makes no specific prediction, or that that the observation does not violate the assumptions of the hypothesis.

\begin{tabular}{|c|c|c|c|c|c|c|}
\hline Observation & Population structure & Capture bias & Fill-in & Ideal-free & Variance sensitivity & Trade-off \\
\hline $\begin{array}{l}\text { Individuals from same } \\
\text { groups seen at both sites }\end{array}$ & no & 1 & yes & yes & yes & yes \\
\hline $\begin{array}{l}\text { LESA and SESA }{ }^{1} \text { show } \\
\text { same mass difference }\end{array}$ & no & yes & no & yes & yes & yes \\
\hline $\begin{array}{l}\text { WESA }^{2} \text { at other sites } \\
\text { show same mass difference }\end{array}$ & no & yes & no & no & l & yes \\
\hline $\begin{array}{l}\text { Body mass distribution } \\
\text { shifted upwards on } \\
\text { Fraser estuary }\end{array}$ & l & no & yes & yes & yes & yes \\
\hline $\begin{array}{l}\text { Variance in fat gain same } \\
\text { on both sites }\end{array}$ & 1 & 1 & / & 1 & no & 1 \\
\hline $\begin{array}{l}\text { Fattening rates higher } \\
\text { at Sidney Island }\end{array}$ & 1 & / & no & no & l & yes \\
\hline $\begin{array}{l}\text { Predator danger higher } \\
\text { at Sidney Island }\end{array}$ & 1 & 1 & / & l & 1 & yes \\
\hline
\end{tabular}

${ }^{1}$ LESA = least sandpiper; SESA = semipalmated sandpiper; ${ }^{2} \mathrm{WESA}=$ western sandpiper. 
The population-structure hypothesis failed all three of its predictions, and we feel confident in rejecting it as an explanation for the body-mass differences. The capture bias hypothesis was able to accommodate the fact that similar body-mass differences are found in other species at our study sites, and at other small and large sites, but neither cumulative frequency distributions of body mass nor stopover times matched expectations based on this mechanism. The fill-in hypothesis failed three of five predictions. In particular, it predicted that Sidney Island is a poorer feeding site whereas the triglyceride measures show it to be better. The basis of the ideal free distribution hypothesis, that heavier birds were able to dominate the better site, was completely untenable. The variancesensitivity hypothesis failed its critical prediction that variance is higher on Sidney Island; if anything the reverse is true.

Several studies on migrating or wintering birds describe situations resembling that explored here. Lindström (1990) recorded stopover habitats (beech forest or field) of bramblings Fringilla montifringilla on southward migration in Sweden in different years. He concluded that forest use slowed migration because feeding was poorer than in fields, but that the latter were more dangerous. Forest use was higher when beech mast was more abundant. Cresswell (1994) showed that wintering adult redshanks Tringa totanus on a Scottish estuary fed on mussel beds, while juveniles fed on nearby salt marshes, where the rate of intake was 1.7 times higher, but mortality to raptors 4.8 times greater. Dierschke (1998) observed that feeding rates and predation risk were both relatively high for juvenile dunlins Calidris alpina at Helgoland in the North Sea.

Lindström (1990) ascribes brambling habitat choice to an informed, facultative choice made by individual birds to maximize the probability of successful migration (see discussion in Alerstam and Lindström 1990, p. 348). Similarly, we surmise that western sandpipers make a facultative choice of stopover site as they arrive in the Strait of Georgia area from their trans-Gulf of Alaska flight. Site selection could be based on sampling, experience, and even innate knowledge about specific or general site characteristics (Moore and Aborn 2000). As in Lindström's hypothesis, we suggest that site choice is made to maximize the probability of successful migration. The evaluation of the trade-off is likely complicated, because it involves temporal (refueling at dangerous sites shortens the necessary exposure time), condition (low body mass birds require more fuel before migration can proceed) and escape (low body mass birds are less vulnerable) components.

It is conceivable that sandpipers move between feeding sites during the stopover duration of about $3.5 \mathrm{~d}$ (see the capture-bias hypothesis section above). A single withinyear sighting on the Fraser estuary of a western sandpiper marked at Sidney Island confirms that individuals can move between sites at least once during their stay, though we as yet have no way of estimating how often this may occur. However, daily commuting between Sidney Island and the Fraser estuary seems unlikely: though low tides occur approximately $45 \mathrm{~min}$ later at the Fraser estuary than at Sidney Island and could offer extra feeding time, the one-way flight distance of $35 \mathrm{~km}$ would require most of this extra time. Individuals marked at Sidney Island were frequently sighted feeding on the surrounding beaches at high tide, and the existence of roosts at both sites suggest that most sandpipers reside at a single location, at least throughout a single tidal cycle.

Our sighting rate of falcons during July and August ranged from $0.09-0.41$ falcons per field hour at both locations. These measures confirm that danger is often present, but attacks and kills are not witnessed often enough for reliable estimates, and we used the distanceto-cover of feeding sandpipers as a measure of danger. The observations of Dekker $(1988,1998)$ on our study site and of others elsewhere (e.g. Page and Whitacre 1975) show that falcons hunt more successfully closer to cover. Peregrines have attack speeds of up to $40 \mathrm{~m} \mathrm{~s}^{-1}$, so a western sandpiper feeding $80 \mathrm{~m}$ from cover is within $2 \mathrm{~s}$ flight time of a peregrine attacking from cover. But on open mudflats a covered approach is impossible, and falcon attacks are less successful (Dekker 1998). We hypothesize that the Fraser estuary is a relatively safe site because the great expanses of open space allow western sandpipers to feed far from cover, and not necessarily because there are fewer falcons there.

This study bolsters the idea that predators are important in the evolutionary ecology of avian migration. In general, investigators have emphasized energetic considerations (e.g. Drent and Piersma 1990, Alerstam and Hedenström 1998), though the possible importance of predation danger is gaining wider recognition (Walter 1979, Lindström 1989, 1990, Alerstam and Lindström 1990, Moore et al. 1990, Clark and Butler 1999). The trade-off hypothesis also has implications for the concept of 'habitat quality'. Often this is assessed on the basis of the rate of mass gain, or on body condition measures (e.g. Marra et al. 1998). If applied in this study, these measures would lead to opposing conclusions about which site was of higher quality. Neither conclusion would be complete, because habitat quality depends on both benefits and costs, and the best choice for any individual is conditiondependent.

Acknowledgements - Gary Kaiser initiated the Canadian Wildlife Service sandpiper banding program in the Strait of Georgia 25 years ago, and caught many of the birds whose weights are reported here. We are grateful for his vision and generosity. Help in the field in recent years was provided by Laura Bosschieter, James Burns, Darren Lissimore, Silke Nebel, Pat O'Hara, Jon Tang, Tony Williams, and Janet Yu. Katie O'Reilly kindly made available to us data not directly accessible in her thesis. We thank Rob Magrath for his input on shaping the final manuscript. The work described here was carried out with banding permits from the Canadian Wildlife Service and Animal Care permits from Simon Fraser University. British Columbia Parks gave permission to work at 
Sidney Island. The work has been supported by the Canadian Wildlife Service, the Wildlife Ecology Chair at Simon Fraser University and the National Science and Engineering Research Council of Canada.

\section{References}

Alerstam, T. and Lindström, Å. 1990. Optimal bird migration: the relative importance of time, energy and safety. - In: Gwinner, E. (ed.). Bird Migration: Physiology and Ecophysiology. Springer-Verlag, Berlin, pp. 331-351.

Alerstam, T. and Hedenström, A. 1998. The development of bird migration theory. - J. Avian Biol. 29: 343-369.

Butler, R. W. and Kaiser, G. W. 1995. Migration chronology, sex ratio, and body mass of least sandpipers in British Columbia. - Wilson Bull. 107: 413-422.

Butler, R. W., Kaiser, G. W. and Smith, G. E. J. 1987. Migration chronology, length of stay, sex ratio, and weight of western sandpipers (Calidris mauri) on the south coast of British Columbia. - J. Field Ornithol. 58: 103-111.

Butler, R. W., Delgado, F. S., de la Cueva, H., Pulido, V. and Sandercock, B. K. 1996. Migration routes of the western sandpiper. - Wilson Bull. 108: 662-672.

Butler, R. W., Williams, T. D., Warnock, N. and Bishop, M. A. 1997. Wind assistance: a requirement of migration of shorebirds? - Auk 114: 456-466.

Clark, C. W. and Butler, R. W. 1999. Fitness components of avian migration: a dynamic model of western sandpiper migration. - Evol. Ecol. Res. 1: 443-457.

Cowlishaw, G. 1997. Trade-offs between foraging and predation risk determine habitat use in a desert baboon population. Anim. Behav. 53: 667-686.

Cresswell, W. 1994. Age-dependent choice of redshank (Tringa totanus) feeding location: profitability or risk? - J. Anim. Ecol. 63: 589-600.

Dekker, D. 1988. Peregrine falcon and merlin predation on small shorebirds and passerines in Alberta. - Can. J. Zool. 66: $925-928$.

Dekker, D. 1998. Over-ocean flocking by Dunlins, Calidris alpina, and the effect of raptor predation at Boundary Bay, British Columbia. - Can. Field-Nat. 112: 694-697.

Dick, W. J. A., Piersma, T. and Prokosch, P. 1987. Spring migration of the Siberian Knots Calidris canutus canutus: results of a co-operative Wader Study group project. - Ornis Scand. 18: 5-16.

Dierschke, V. 1998. High profit at high risk for juvenile dunlins Calidris alpina stopping over at Helgoland (German Bight) - Ardea 86: 59-69.

Drent, R. H. and Piersma, T. 1990. An exploration of the energetics of leap-frog migration in Arctic breeding waders. - In: Gwinner, E. (ed.). Bird Migration: Physiology and Ecophysiology. Springer-Verlag, Berlin, pp. 399-412.

Guillemette, M., Ydenberg, R. C. and Himmelman, J. H. 1992 The role of energy intake rate in prey and habitat selection of common eiders Somateria mollissima in winter: a risk-sensitive interpretation. - J. Anim. Ecol. 61: 599-610.

Houston, A. I. 1999. Models of optimal avian migration: state, time and predation. - J. Avian Biol. 29: 395-404.

Houston, A. I., McNamara, J. M. and Hutchinson, J. M. C. 1993. General results concerning the trade-off between gaining energy and avoiding predation. - Phil. Trans. R. Soc. Lond. B 341: 375-397.

Iverson, G. C., Warnock, S. E., Butler, R. W., Bishop, M. A and Warnock, N. 1996. Spring migration of western sandpipers along the Pacific coast of North America: a telemetry study. - Condor 98: 10-21.

Jenni-Eiermann, S. and Jenni, L. 1994. Plasma metabolite levels predict individual body-mass changes in a small, long-distance migrant, the Garden Warbler. - Auk 111: 888-889.
Lima, S. L. 1986. Predation risk and unpredictable feeding conditions: determinants of body mass in birds. - Ecology 67: $377-385$.

Lima, S. L. and Dill, L. M. 1990. Behavioral decisions made under the risk of predation: a review and prospectus. - Can. J. Zool. 68: 619-640.

Lindström, Å. 1989. Finch flock size and risk of hawk predation at a migratory stopover site. - Auk 106: 225-232.

Lindström, A. 1990. The role of predation risk in stopover habitat selection in migrating bramblings, Fringilla montifringilla. - Behav. Ecol. 1: 102-106.

Lindström, A. 1998. Mass and morphometrics of Little Stints Calidris minuta on autumn migration along the Arctic coast of Eurasia. - Ibis 140: 171-174.

Lissimore, D., Lemon, M., Lank, D. B., Butler, R. W. and Ydenberg, R. C. 1999. Large and consistent body mass differences of migrating small Calidris sandpipers at adjacent stopover sites. - Wader Study Group Bull. 88: 55-58.

Marra, P. P., Hobson, K. A. and Holmes, R. T. 1998. Linking winter and summer events in a migratory bird by using stable-carbon isotopes. - Science 282: 1884-1886.

Moore, F. R. and Simm, P. A. 1986. Risk-sensitive foraging by a migratory bird (Dendroica coronata). - Experientia 42: 1054-1056.

Moore, F. R. and Aborn, D. A. 2000. Mechanisms of en route habitat selection: how do migrants make habitat decisions during stopover? - Stud. Avian Biol. 20: 34-42.

Moore, F. R., Kerlinger, P. and Simons, T. R. 1990. Stopover on a Gulf coast barrier island by spring trans-Gulf migrants. - Wilson Bull. 102: 487-500.

Morrison, R. I. G. 1984. Migration systems of some new world shorebirds. - In: Burger, J. and Olla, B. L. (eds). Shorebirds: Migration and Foraging Behavior. Plenum Press, New York, pp. 125-202.

O’Reilly, K. M. 1995. Ecological basis of endocrine phenomena: field studies of Scolopacidae as model systems. - Ph.D. thesis, University of Washington, Seattle, Washington.

Page, G. W. and Fearis, B. 1971. Sexing western sandpipers by bill length. - Bird-Banding 42: 297-298.

Page, G. W. and Whitacre, D. F. 1975. Raptor predation on wintering shorebirds. - Condor 77: 73-83.

Piersma, T. and Jukema, J. 1993. Red breasts as honest signals of migratory quality in a long-distance migrant, the bartailed godwit. - Condor 95: 163-177.

Sandercock, B., Lank, D. B. and Cooke, F. 1999. Seasonal declines in the fecundity of arctic-breeding sandpipers: different tactics in two species with an invariant clutch size. - J. Avian Biol. 30: 460-468.

Stephens, D. W. and Krebs, J. R. 1986. Foraging Theory. Princeton University Press, Princeton, New Jersey.

Sutherland, W. J. and Parker, G. A. 1985. Distribution of unequal competitors. - In: Sibly, R. M. and Smith, R. H. (eds). Behavioural Ecology: Ecological Consequences of Adaptive Behavior. Blackwell Scientific Publications, Oxford, pp. 255-273.

van der Veen, I. and Lindström, A. 2000. Escape flights of yellowhammers and greenfinches: more than just physics. Anim. Behav. 59: 593-601.

Walter, H. 1979. Eleonora's Falcon: Adaptations to Prey and Habitat in a Social Raptor. - University of Chicago Press, Chicago.

Warnock, N. and Bishop, M. A. 1998. Spring stopover ecology of migrant western sandpipers. - Condor 100: 456-467.

Williams, T. D., Guglielmo, C. G., Egeler, O. and Martyniuk, C. 1999. Plasma lipid metabolites provide information on mass change over several days in captive western sandpipers (Calidris mauri). - Auk 116: 994-1000.

Zar, J. H. 1984. Biostatistical Analysis. - Prentice-Hall, Englewood Cliffs, NJ

(Received 23 March 2000, revised 27 April 2001, accepted 10 May 2001.) 